\title{
Juvenile localized scleroderma
}

\author{
*Luis Zavaleta-Medina ${ }^{1}$, P W Sánchez G², Karen E Sánchez Ramirez ${ }^{2}$, Diego A Cedamanos Alva ${ }^{3}$, Jose \\ Caballero $^{2}$
}

Sri Lanka Journal of Child Health, 2019; 48(4): 364-366

DOI: http://dx.doi.org/10.4038/sljch.v48i4.8839

(Keywords: Juvenile localized scleroderma, atrophy, methylprednisolone)

\section{Introduction}

Scleroderma is an autoimmune disease, where there is inflammation and fibrosis due to a large accumulation of collagen ${ }^{1,2}$. There are two types viz. systemic sclerosis, in which there is diffuse cutaneous sclerosis and involvement of internal organs, and juvenile localized sclerosis (JLS), represented by cutaneous involvement beyond the systemic vascular or internal organ involvement ${ }^{3}$. JLS is a rare pathology worldwide, having an incidence rate of between $0.4-2.7$ per 100,000 people/year ${ }^{4}$. We present a child with JLS with atrophy of the lower limbs.

\section{Case report}

A previously healthy 5-year-old boy presented with no relevant history. One year ago his disease began with weakness and progressive muscular atrophy of the lower limbs, in addition to hypopigmented lesions on the anterior aspect of the right thigh. Nine months before admission, these symptoms intensified, preventing him from walking, which is why he received physiotherapy for a short time. Muscle atrophy increased, the hypopigmented lesions extended, and there was joint stiffness in both knees with pain. Patient came to our hospital due to the presence of ulcerative necrotic lesions on

${ }^{1}$ Hospital Victor Lazarte EsSalud Trujillo, Perú, ${ }^{2}$ Universidad Privada Antenor Orrego, Peru,

${ }^{3}$ Universidad Privada Antenor Orrego Trujillo La Libertad, Peru

*Correspondence: luzavaleta@hotmail.com

orcid.org/ 0000-0002-2995-3433

(Received on 26 June 2018: Accepted after revision on 20 July 2018)

The authors declare that there are no conflicts of interest

Personal funding was used for the project.

Open Access Article published under the Creative

Commons Attribution CC-BY (c) (i) the skin associated with thermal elevation and signs of phlogosis in both knees (Figure 1).

Physical examination revealed diffuse hypopigmented lesions in both lower limbs, with a predominance of the right leg with a stiff, whitish texture, and atrophy of severe muscle mass, decreased strength and sensitivity, and severe stiffness in both knees (Figure 2).

Complete blood count showed a total leucocyte count of $16,080 / \mathrm{cu} \mathrm{mm}$, predominantly neutrophils, a haemoglobin level of $9.9 \mathrm{~g} / \mathrm{dl}$ and a platelet count of $682,000 / \mathrm{cu} \mathrm{mm}$. Coagulation tests, cardiac enzymes, glucose, urea, creatinine, serum electrolytes, urine test, ferritin, parathyroid hormone and liver profile were within appropriate reference values. Antinuclear antibody (ANA) was 0.37 (positive ratio: $\geq 1.0$ ).

In the skin biopsy, the sample of the thin plate in the epidermis showed orthokeratosis and vacuolar degeneration of the basal layer. In the dermis there were thickened, collagen fibres and eosinophils with presence of a superficial perivascular lymphoplasmacytic infiltrate. In the thick plate sample, there was hyperkeratosis in the epidermis. In the dermis, there were thickened collagen fibres and eosinophils with a lymphoplasmacytic infiltrate of superficial perivascular distribution. Histological changes were consistent with scleroderma.

Treatment was started with oxacillin (150 $\mathrm{mg} / \mathrm{kg} /$ day) intravenously (IV) and clindamycin (30 $\mathrm{mg} / \mathrm{kg} /$ day) IV for 14 days. After obtaining the result of the biopsy, he received a pulse of methylprednisolone. There was a distinct clinical improvement. The white cell count and haemoglobin level were found to be normal; however, the platelet count continued to increase $(653,000 / \mathrm{cu} \mathrm{mm})$. Patient was referred to a Dermatological Unit in a hospital centre of greater complexity for specific and integral management. 


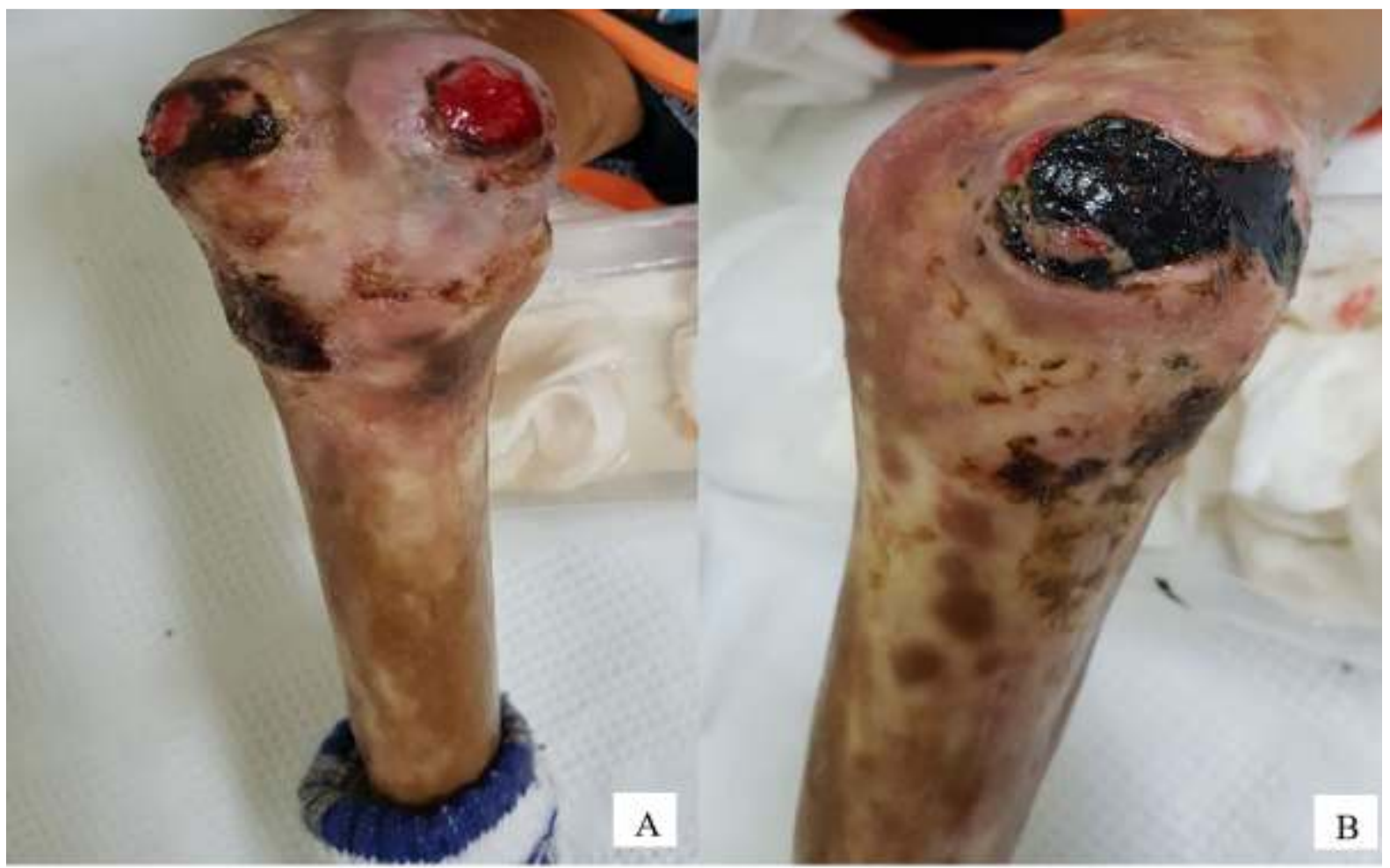

Figure 1: Necrotic ulcerative lesions in right knee (A) and left knee (B)
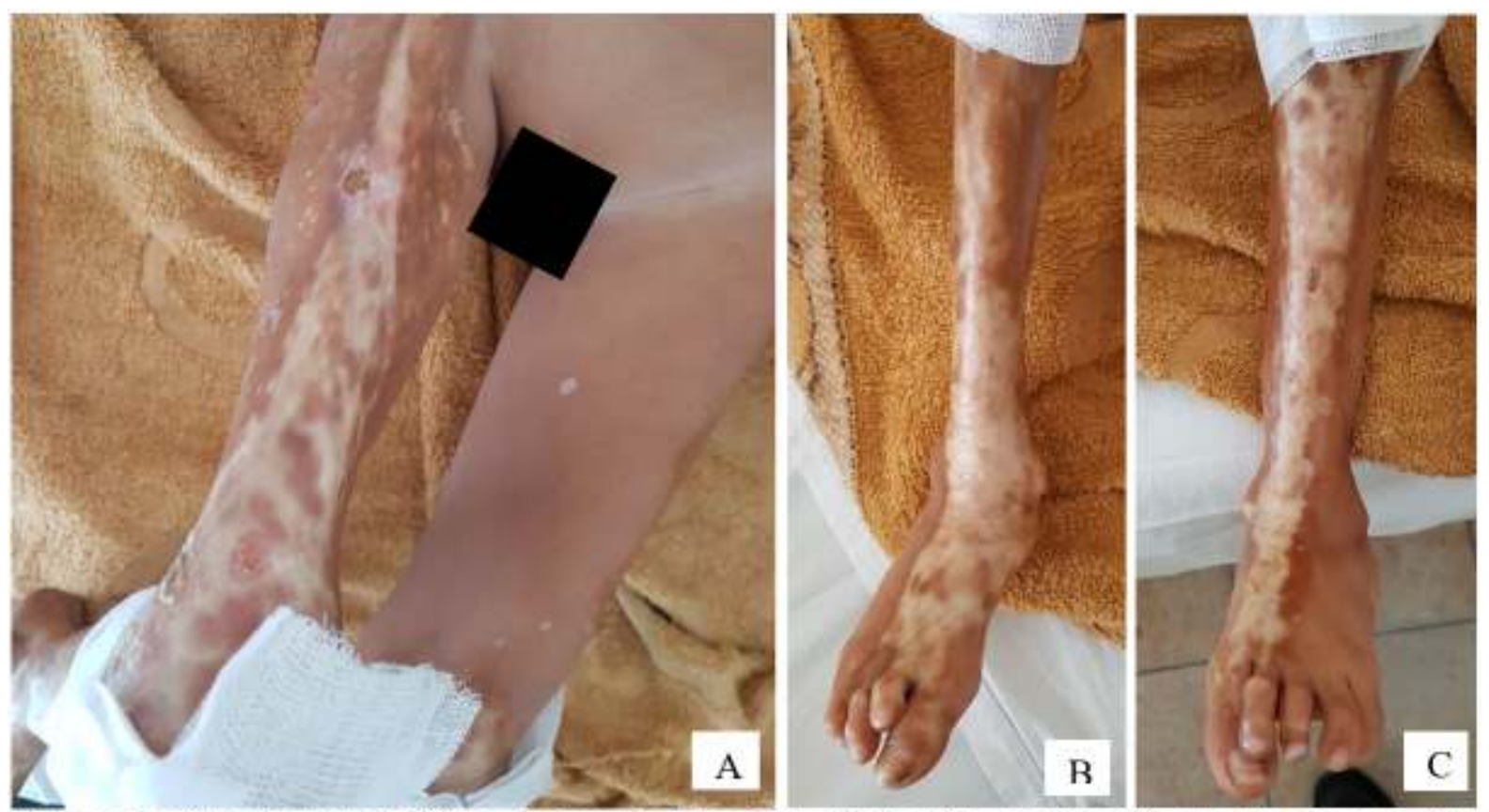

Figure 2: Hypopigmented diffuse lesions in the right thigh with atrophy of muscular groups (A), hypopigmented lesions, muscle atrophy and foot deformity, right side (B) and left side (C)

\section{Discussion}

Although the aetio-pathogenesis is still unknown, some intervening factors may include trauma, radiation, medications, viral and/or bacterial infections, autoimmunity and microchimerism. In predisposed individuals, it would cause an increase in cytokines (interleukins 2, 4, 6 and growth factors), fibroblast proliferation, collagen synthesis and fibrosis. The interaction of three events which generate the clinical characteristics of this disease has been demonstrated: inflammatory, fibrotic and vascular components ${ }^{4,5}$. These events are clinically related to dermal and subdermal atrophy, which are manifested by cutaneous thinning, depression or concavity of the affected area, and induration as seen 
in Figure 2 and contrasts with the result of the histopathological study of our patient.

For JLS, several classifications have been proposed, with Laxer and Zulian being the most used ${ }^{5}$. In this we have 5 main presentations: circumscribed, generalized, linear, mixed, that is a combination of circumscribed and linear or generalized and linear; and the pansclerotic or deep form, which affects the entire skin $^{6}$.

The diagnosis of JLS is based on the clinical characteristics supported by biopsy of the skin and subcutaneous tissues ${ }^{3}$. Although the treatment is still generally unsatisfactory, it should be considered in terms of the extent and severity of the disease, beginning in the early stages before deforming complications or limitation of mobility appear ${ }^{5,7,8}$. Topical glucocorticoid, tacrolimus, and vitamin D analogues may be used. Systemic medications such as corticosteroids, methotrexate, cyclosporine, infliximab are also useful, and UVA phototherapy may be useful ${ }^{9}$. The duration of treatment with methotrexate is not fully established. It has been used for prolonged periods of up to 2 years without complications, and the consensus is to treat for at least 2 years, less time favouring relapses ${ }^{3}$. Our patient was treated only for two days with intravenous methylprednisolone, and the decision was made to refer him to another hospital of greater complexity for integral management.

\section{References}

1. Aranegui B, Jiménez-Reyes J. Morphea in childhood: An update. Actas DermoSifiliográficas 2018; 109(4): 312-22. https://doi.org/10.1016/j.adengl.2018.03.0 11

PMid: 29248149

2. Arango $\mathrm{C}$, Malagón $\mathrm{C}$, Gómez $\mathrm{M}$, Mosquera C, Yépez R, González T et al. Juvenile localized scleroderma: Is it a benign disease? Rev Colomb Reumatol. 2017; 24(3):129-30. https://doi.org/10.1016/j.rcreue.2017.08.0 02
3. Strickler A, Gallo S, Jaramillo P, de Toro G. Morphea or juvenile localised scleroderma: Case report. Rev Chil Pediatría. 2016; 87(4):279-83.

https://doi.org/10.1016/j.rchipe.2016.01.0 13

PMid: 26976080

4. Moinzadeh P, Hunzelmann N, Kreuter A, Krieg T. Localized scleroderma: a review. Journal of Scleroderma and Related Disorders 2016; 1(3):286-97.

https://doi.org/10.5301/jsrd.5000215

5. Pico Valimaña M. Morfea lineal. Piel. 2017; 32(2):73-9.

https://doi.org/10.1016/j.piel.2016.06.007

6. NK S. Scleroderma in the common orthopaedic practice: A review. 2016; 1(1):3.

7. Careta MF, Romiti R. Localized scleroderma: clinical spectrum and therapeutic update. An Bras Dermatol. 2015; 90(1):62-73.

https://doi.org/10.1590/abd18064841.2015 2890

PMid: 25672301 PMCid: PMC4323700

8. Bielsa Marsol I. Update on the Classification and Treatment of Localized Scleroderma. Actas Dermo-Sifiliográficas. 2013; 104(8):654-66.

https://doi.org/10.1016/j.adengl.2012.10.0 12

PMid: 23948159

9. Asghar A, Riaz S, Ahmad TJ. Generalized morphea - a case report. Journal of Pakistan Association of Dermatology 2017; 27(2): 180-2. 